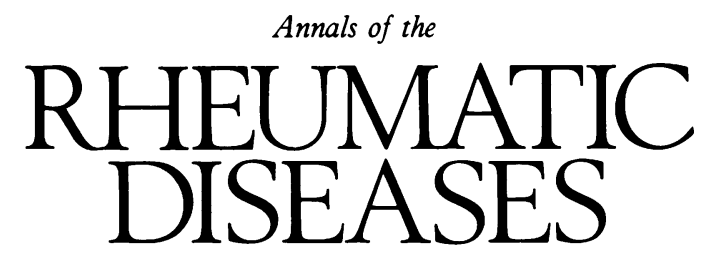

\title{
Leader
}

\section{Population projections and the effect on rheumatology}

Much is said in the press about the aging of the population and the effect it will have on all aspects of life. The implications of the changing age structure affect us directly. We are thinking about the consequences of our own aging and that of our own families and friends, whether it be in an older generation, our own generation, or that of our children and their children. This paper considers the potential impact on rheumatology as a specialty and then looks more generally at some of the other consequences of an increasing number of people with rheumatic disorders in the population.

One of the most important determinants of the age structure of the population in the future is the current situation. Figure 1 shows the estimated resident population of the United Kingdom by single years of age in mid-1986. ${ }^{1}$ The major features to note are the peaks of births in 1920 (following the great flu epidemic in 1918), in 1947 (the postwar baby boom), and the more sustained peak around 1964. Separating these peaks are troughs when the birth rate was comparatively lower.

It is the pattern in the past number of births which is the most important factor accounting for changes in age structure projected for the short and medium term future. Not only will the current population age, but a peak in the birth rate is likely to give rise to a further, although more spread out, peak a generation later. A further major factor is a gradual increase in the proportion of each successive birth cohort which survives to reach old age. Three decades ago

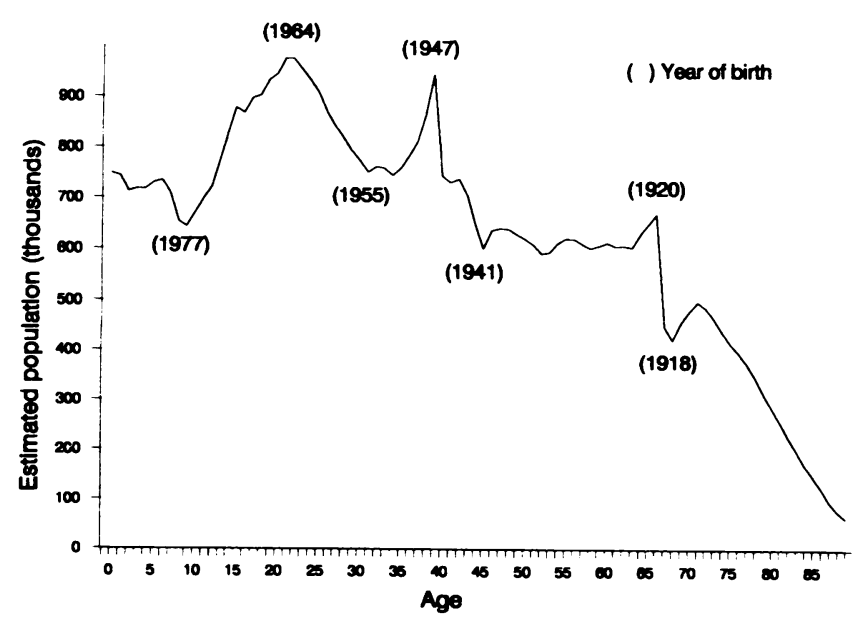

Figure 1 Estimated resident population by single years of age in mid-1986, United Kingdom. the average expectation of life at birth was 69 years, it is now 74 years, and three decades hence it is likely to reach $77 .^{1}$

The net effect of these changes is shown in the population projections for the coming decades. ${ }^{2}$ Overall, the total number of the people in the population of the United Kingdom is estimated to change little, from 56.73 million in 1990 , through a high of 60.12 million in 2025 . The major changes to be expected are those in the relative proportion of the people in different age groups. In $198515 \%$ of the population were aged 65 years and older; by 2030 the proportion will be $20 \%$. Figure 2 shows population projections for the proportion of people in different age groups as a proportion of the distribution in 1985 . It should be remembered that these are only projections and are as such best estimates. These may be subject to error, particularly for more distant years. ${ }^{2}$ Base population figures for 1985 are shown in table 1 .

Changes in the proportion of different age groups are not uniform. Although overall the population is getting older, the effect on different age groups comes in waves. Over the years there will be a decline in the proportion of people aged 44 years and younger (fig $2 a$ ) and a slight increase in the proportion aged 45-64 years, with a peak in the second and third decades of the new century (fig 2b). The most significant feature is the relative increase in the proportion of the population aged 65 years and older, particularly those aged 75 years and older (fig $2 \mathrm{c}$ ).

The oldest age groups are likely to include a disproportionate number of women, which in part reflects the differential mortality at all ages. Large numbers and proportions of persons aged 65 years and older live alone; at the time of the 1981 census almost a third of older persons lived alone, and almost half lived with a spouse only. ${ }^{3}$ Within this group the patterns vary by age. For example, as might be expected, the group aged 85 years and older had the highest incidence of widowhood and accordingly they were most likely either to live alone or with their children or siblings. Older persons are less likely to have earnings as a

Table 1 United Kingdom population, $1985^{2}$

\begin{tabular}{llllrrrrl}
\hline \multicolumn{8}{c}{ Age group } \\
\cline { 2 - 8 } & $0-4$ & $5-14$ & $15-24$ & $25-44$ & $45-64$ & $65-74$ & $75+$ & All ages \\
\hline Men & 1850 & 3743 & 4740 & 7769 & 6104 & 2165 & 1202 & 27574 \\
Women & 1760 & 3544 & 4547 & 7670 & 6332 & 2775 & 2416 & 29044 \\
Persons & 3610 & 7287 & 9287 & 15439 & 12436 & 4940 & 3618 & 56618 \\
\hline
\end{tabular}




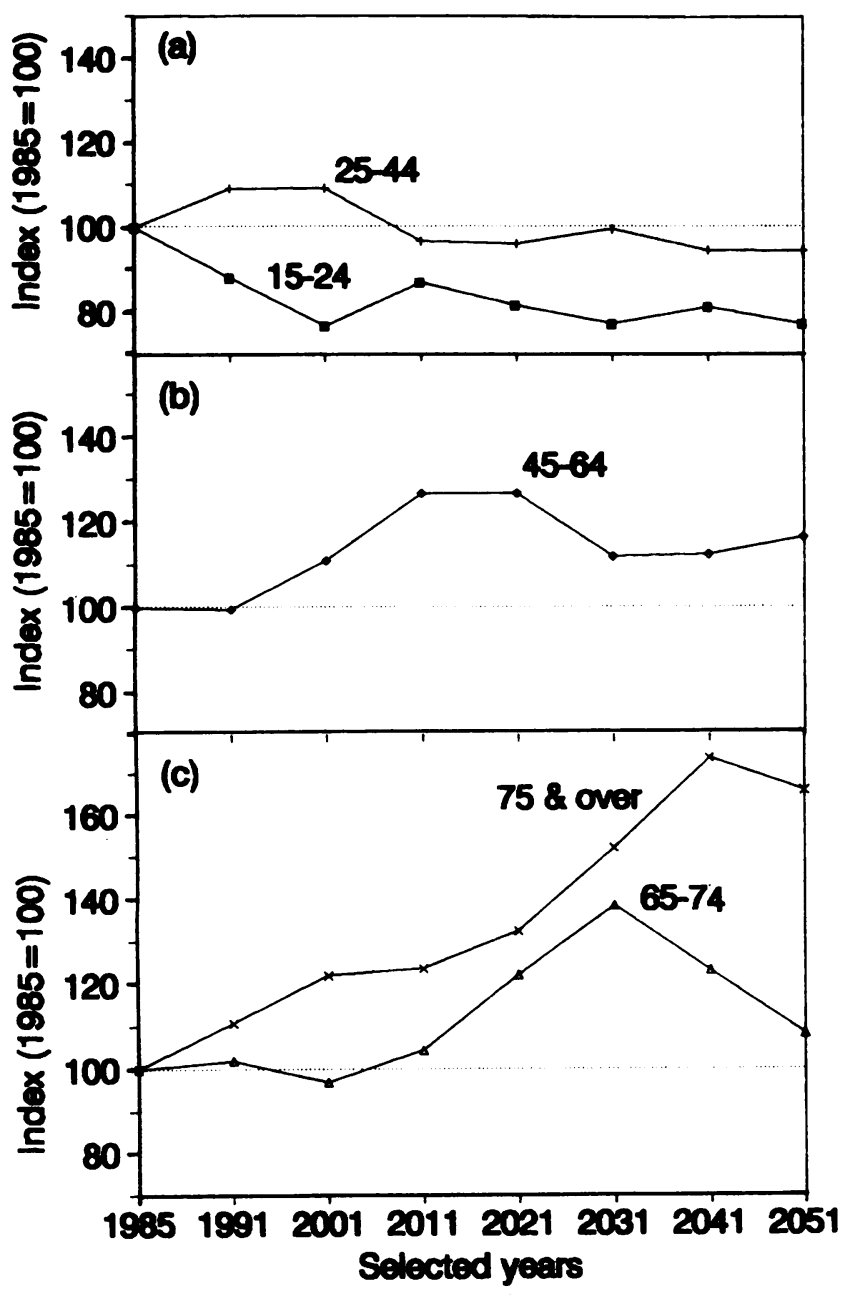

Figure 2 Projected changes in the age structure of the United Kingdom population, 1985-2051: proportions in selected age groups indexed to the population in 1985.

source of - income, and are mostly dependent on state pensions and other social security benefits. They are also likely to live in poorer housing circumstances. 34

All things being equal an increase in the proportion of people in the population in middle and later life is likely to be accompanied by an increase in the experience of rheumatic disorders in the population, as many of these disorders are either directly related to the aging process, or increase in incidence with age.

It is difficult to get data to gauge the impact on rheumatology as a specialty. It is primarily an outpatient specialty, but unfortunately data on the characteristics of the population attending outpatient clinics are not available. A further aspect is the nature of rheumatological practice. In some practices, particularly in the teaching centres, the bulk of consultations is likely to be dominated by the arthropathies, particularly rheumatoid arthritis. In the district general hospitals, however, the patient load is likely to reflect a wider diagnostic spectrum, with more consultations for soft tissue and back disorders. Depending on the diagnostic mix in a practice the effect may be differently felt.

Epidemiological estimates are of limited use in this context as by no means all those with symptoms are likely to consult. One indicator of the potential need for a specialist rheumatological opinion is the number of patients attending a general practitioner. Although referral rates will vary between practitioners and from locality to locality, nevertheless this does represent the source from which most rheumatology patients come.
Table 2 Type of rheumatic disorder-content of categories and related ICD numbers - shown in fig 3

\section{Arthropathy}

Rheumatoid arthritis and allied conditions $(714,720 \cdot 0)$; osteoarthritis

(osteoarthrosis) and allied conditions (715); gout (274); traumatic arthropathy (716.1); swelling of joint, effusion of joint (719.0); pain in joint, arthralgia, stiffness in joint $(719.4,719.5)$; other types of arthritis and diffuse connective tissue disorders (710-713, 716 (except $716 \cdot 1), 710 \cdot 2,719 \cdot 3,725)$; osteoarthritis of spine (721)

\section{Back disorders}

Back pain (lumbar, thoracic, or sacroiliac) without radiating symptoms $(720 \cdot 1-720 \cdot 9,724 \cdot 1,724 \cdot 2,724 \cdot 5-724 \cdot 9)$; syndromes related to the cervical spine $(722 \cdot 0,722 \cdot 4,723)$; prolapse or degeneration of lumbar intervertebral disc, sciatica $(722 \cdot 1(\mathrm{pt}), 722 \cdot 5(\mathrm{pt}), 724 \cdot 3)$; other back pain with radiating symptoms (including displacement of thoracic disc) $(722 \cdot 1(\mathrm{pt}), 722 \cdot 5(\mathrm{pt}), 724 \cdot 4)$; acquired (including displacement of thoracic disc) $(722 \cdot 1(\mathrm{pt}), 722 \cdot 5(\mathrm{pt}), 724 \cdot 4)$; acquired
deformities of spine (737); sprains and strains of rest of vertebral column (846, deformities of spine (737); sprains
$847 \cdot 1-847 \cdot 9)$ or neck $(847 \cdot 0)$.

\section{Rheumatism}

The shoulder syndromes $(726 \cdot 0-726 \cdot 2)$; other bursitis, tendinitis, tenosynovitis, synovitis and peripheral enthesopathy (726.3-726.9, 727 (except 727.1, 721.4)); other non-articular rheumatism and disorders of muscle, ligament and fascia (728, 729) (except $729 \cdot 5,729 \cdot 8)$ ); pain and other symptoms referable to limbs $(729.5$, 729.8); chronic internal derangement of knee (717)

\section{Trauma}

Acute damage to meniscus of knee $(836 \cdot 0-836 \cdot 2)$; all other dislocations and subluxations (Rdr 830-839); sprains and strains of: shoulder, upper arm, elbow, forearm (840-841); wrist, hand, finger (842); knee, (lower) leg (844); ankle $(845 \cdot 0)$; foot, toe $(845 \cdot 1)$; all other sprains and strains ( $\operatorname{Rdr} 840-848)$

To attempt to look at what this might mean for rheumatology I have taken figures from the morbidity survey in general practice and attempted to look at the implications in the light of the changes in the population structure. ${ }^{5}$ There are a number of assumptions in doing this. Firstly, it assumes that the population projections themselves turn out to be right. Secondly, that the pattern seen in the morbidity statistics in general practice is representative of the population as a whole and will continue over time. A third assumption is that the referral patterns between primary care and specialist care will be maintained. If this is so, then one might expect changes in the number of people consulting their general practitioners to be reflected by changes in the work load of hospital specialists. The net effect should set some course estimates and serve as food for thought.

Figure 3 shows the age pattern of patients consulting for major classes of rheumatic disorder. On the whole the patient consulting rates for arthropathies increase with age. The most commonly specified diagnosis in this group is osteoarthrosis, though the ratio of rates for patients consulting for osteoarthrosis and rheumatoid arthritis changes with age from $1 \cdot 7: 1$ for the $25-44$ age group to $7 \cdot 4: 1$ for those

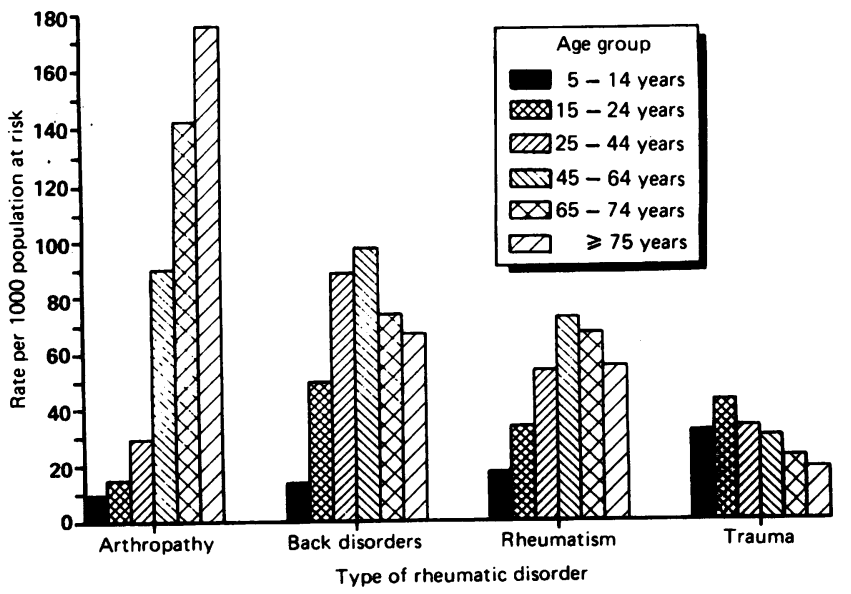

Figure 3 Age pattern of patients consulting rates for general practice for selected types of rheumatic disorder; rate per 1000 population at risk by age group. The type of rheumatic disorder - content of categories and related ICD numbers - is shown in table 2 
aged 75 years and older. The patient consulting rates for back disorders and rheumatism (soft tissue disorders) are highest in middle life. Patients consulting with trauma, mainly sprains and strains, are, as might be expected, on the whole somewhat younger. Referral rates inevitably differ between conditions. For example, $9.4 \%$ of those with rheumatoid arthritis and allied disorders are referred, as are $6.1 \%$ of those with osteoarthrosis and allied disorders (excluding osteoarthritis of the spine) and 3.3\% of those with low back pain. The above are total figures for referral either as an outpatient, an inpatient, or for a private consultation, and do not give information about the specialty to which the referral was made.

If the status quo of the pattern of patients consulting and referral in general is maintained the effect of the changing age structure of the population is likely have an impact both on general practice and on rheumatology. There is likely to be a steady and disproportionate increase in the number of patients consulting with various types of arthritis, particularly those aged 75 years and older, though the increases in the proportion of the population aged 45-64 years and 65-74 years is also likely to be a factor (figs $2 b$ and $c$ ). Increases in the proportion of the population aged 25-44 and 45-64 in the earlier decades of the next century may well result in a relative increase in referrals for back pain and soft tissue rheumatism.

The discussion above has considered the implications for rheumatology rather narrowly; a more general aspect is the impact on the population as a whole. Surveys of the population show that the prevalence of musculoskeletal morbidity and joint complaints increases steeply with age. ${ }^{6-8}$ This increase is seen both in overall prevalence of musculoskeletal disorders, and in severity in terms of the number of joints reported as affected and the impact on the individual such as disability. The increase in the prevalence of joint troubles is accompanied by an increase in the proportion of each age group who have difficulty or dependence in certain everyday living activities. ${ }^{8}$ Surveys of disablement in the population have consistently shown musculoskeletal disorders to be the major cause of disability, and that the prevalence of musculoskeletal disability increases markedly with age. ${ }^{9-12}$

This has implications for the care needed for this section of the population. Important concerns are disability leading to mobility restriction and to need for help with everyday living activities. ${ }^{11} \mathrm{~A}$ survey of the population of Calderdale, West Yorkshire, England, showed that more than half of those aged 85 or older had joint troubles, and, of these, most reported having some disabilities. ${ }^{8}$ Overall, about one third of this age group reported having both joint troubles and being dependent in dressing, getting to and using the toilet, getting in and out of bed, or being unable to get out of the house without being taken.

Care for the elderly is often assumed to be provided by 'the family' or 'children'. In practice, caring does not seem to involve a large network of formal or informal care givers, but more often is provided by a woman werking largely alone. ${ }^{13}$ Increasingly it is found that more than an appreciable proportion of these care givers would themselves be defined as 'elderly' - that is over the age of $65 .{ }^{14}$ If a spouse is not available, care is most commonly provided by a daughter or daughter-in-law or other female relative. Men are less likely to be primary care givers. These care givers have been described as 'women in the middle', juggling responsibilities for their own families with caring for aged parents and paid employment. ${ }^{15}$ At the same time these women may themselves be in those age groups where there is an increasing probability of being affected by arthritis or other rheumatic disorders.

There are many aspects of care giving to be considered.
These include the smaller size of families with fewer siblings to ehoose from in assuming a caring role for elderly parents, geographic mobility with families living further apart, and economic pressure and other social changes leading to women having paid employment outside the home. ${ }^{14} \mathrm{~A}$ further dimension, and one which has received relatively less attention, is the increasing incidence of divorce, which also severs the potential care-giving links between women and their parents-in-law.

Thus the picture is one of increasing morbidity and disability with age. What then is the role of the rheumatologist? The remainder of this paper concerns practical aspects. It does not discuss more technical matters, such as the process of aging, and age related changes that are relevant to the practice of rheumatology (such as changes in pharmacokinetics with age), or those aspects of rheumatology that are particular to the older people, such as polymyalgia rheumatica and ankylosing hyperostosis (Forestier's disease). ${ }^{16}$

We can do nothing about the aging of the population, and with the current state of knowledge there is little that can be done to prevent the onset of most rheumatic disorders. The only possible course of action is to attempt to lessen the impact for people with rheumatic disorders. There have been calls for the focus of health to be on the quality of life rather than its duration, to minimise loss of fitness, and to prevent unnecessary loss of physical ability. ${ }^{17}$

In line with this, an important aspect of care becomes the postponement of the disabling effects of morbidity. Objectives should be to prevent decline in quality of life owing to the development of preventable or treatable symptoms, such as pain, to maintain mobility, and to preserve independence in those with disabilities. A range of modalities may need to be used to reach these objectives, many of which are more the province of rehabilitation and community services, but all are services to which referral might need to be made. These include disease and symptom control, prescription of exercises and treatment to maintain or increase physical fitness and muscle strength, the provision of orthotics or special shoes, the use of aids and adaptations in the home, and so on. ${ }^{18-20}$ Consideration may need to be taken of the needs of older people so that they can remain in their own homes, and to the prevention of breakdown of informal support offered by relatives and friends. ${ }^{21}$

Coping with the increased burden of rheumatic disorders as the population ages will require the provision of appropriate resources. This of course is another story. The flip side to the greying of the population is the relative decline in the proportion of younger people, which has a whole range of ramifications, including financial (less tax payers) and a decrease in the size of the labour force. This also represents a shortage of (wo)manpower for the health and other caring professions, and of those to provide informal care within families.

This paper has brought out a number of issues which are likely to affect the work of the rheumatologist. The changes discussed above suggest an increasing need to be aware of, and perhaps act yet further as a focus for, the marshalling of other types of care and treatment to help stave off the adverse day to day consequences for those affected, such as disability and dependency, and to maintain quality of life. In addition, the typical patient is increasingly likely also to be a care giver for another, so that the adverse consequences of rheumatic disorders may well be amplified within the domestic setting.

This paper has concentrated on the negative aspects of aging and musculoskeletal disability. By no means all elderly people are disabled or dependent. There is a stereotype of the elderly as infirm, disabled, housebound, non-productive, and not participating in society. The reality 
is that most of the young-old and many of the old-old are in good health, living independently, and contributing to their family and the community. Hopefully, with increases in the health status, education, and financial wellbeing of the population the elderly of tomorrow, the products of the postwar welfare state, may be less affected and better equipped to cope with the consequences of chronic disease.

University of Toronto Rheumatic Diseases Unit,

E M BADLEY Wellesley Hospital,

Tumer Wing (Room 650)

160 Wellesley Street East, Toronto,

Ontario M4Y 173, Canada

1 Thompson J. Ageing of the population; contemporary trends and issues. Population Trends 1988; 21: 18-22.

2 Office of Population Censuses and Surveys. Population projections 1985-2025. Series PP2 No 15. London: HMSO, 1987.

3 Family Policies Studies Centre. An ageing population. London: Family Policies Studies Centre, 1984. (Fact sheet.)

4 Hunt A. The elderly: age differences in the quality of life. Population Trends 1978; 11: 10-15.

5 Royal College of General Practitioners, Office of Population Censuses and Surveys, Department of Health and Social Security. Morbidity statistics from Surveys, Department of Health and Social Security. Morbidity statistics

6 general practice $1981-82$. Series MBS No 1. London: HMSO, 1983. and associated disability. Am $\mathcal{F}$ Pub Health 1984; 74: 574-9.

7 Jette A M, Branch L G. Musculoskeletal impairment among the noninstitutionalized aged. Int Rehabil Med 1984; 6: 157-61.
8 Badley E M, Tennant A. The rising tide of joint troubles with increasing age: findings from a postal survey of the population [Abstract]. $B r \mathcal{F}$ herumatol findings from a postal

9 Harris A I. Handicapped and impaired in Great Britain. Part 1. London: HMSO, 1971 .

10 Badley E M, Thompson R P, Wood P H N. The prevalence and severity of major disabling conditions - a reappraisal of the government social survey of the handicapped and impaired in Great Britain. Int $\mathcal{F}$ Epidemiol 1978; 7 : 145-51.

11 Martin J, White A. The prevalence of disability among adults. OPCS survey of disability in Great Britain. London: HMSO, 1988. (Office of Population Censuses and Surveys Social Survey Division, Report 1.)

12 Badley E M, Tennant A. Calderdale Health and Disablement Survey. Main Report. Manchester: ARC Epidemiology Research Unit, University of Manchester, 1988.

13 Jones D A, Vetter N J. A survey of those who care for the elderly at home; their problems and needs. Soc Sci Med 1984; 19: 511-4.

14 Zola I K. Aging, disability and the home-care revolution. Arch Phys Med Rehabil 1990; 71: 93-6.

15 Brody E. Women in the middle and family help to older people. Gerontology 1981; 21: 471-80.

16 Wood P H N, Badley E M. An epidemiological appraisal of bone and joint disease in the elderly. In: Wright V, ed. Bone and joint disease in elderly. London: Churchill Livingstone, 1983: 1-22.

17 Fries J F. Aging, natural death, and the compression of morbidity. $N$ Engl 7 Med 1980; 303: 130-5

18 Chamberlain M A. Mobility of the elderly arthritic. In: Wright V, ed. Bone and joint disease in elderly. London: Churchill Livingstone, 1983: 222-36.

19 Agate J N. Physiotherapy problems and practice in the elderly: a critical evalution. In: Wright $\mathrm{V}$, ed. Bone and joint disease in elderly. London: Churchill Livingstone, 1983: 237-55.

20 Gerber L. H. Aids and appliances. In: Wright V, ed. Bone and joint disease in elderly. London: Churchill Livingstone, 1983: 256-74.

21 Gray M J A. A strategy for health in old age. In: Smith A, ed. Recent advances in community medicine. Vol 3. London: Churchill Livingstone, 1984: 269-78. 